\title{
CUANDO LAS PALABRAS SE DESVANECEN EN LA NOCHE CALLADA DE JOSÉ ANTONIO PÉREZ GOLLÁN (1937-2014)
}

\author{
Lautaro Núñez $A .^{1}$
}

\author{
Desembocamos al silencio \\ en donde los silencios \\ enmudecen... \\ Octavio Paz
}

De mirada fija y profunda, discreto de estatura $\mathrm{y}$ alto de convicciones, delicado en el vestir, de rostro moreno acriollado, no parecía descender de los barcos, sino de las profundidades latinoamericanas al punto que por su andinidad, con algo del cantito cordobés, en principio no se le reconocía bien su país de origen. Vivía la paradoja de ser del "interior" y por su habla obviamente que no era "porteño", pero sí un ser esencialmente urbano y amaba a su Buenos Aires desde un piso grande y dominante en el centro tradicional, en esos edificios patrimoniales con ascensor pequeño de puerta de corredera. Es de esos departamentos tan propios de los investigadores argentinos: su escritorio cubierto de papeles, notas de campo, manuscritos, muestras en análisis, recuerdos de su casa natal de Córdoba, su música que no era precisamente la típica y su muy querida biblioteca. Allí podíamos hacernos cargo de nuestros temas preferidos: shamanismo y alucinógenos, lo último de Aguada, el rol social de los museos, la autonomía de los procesos sur andinos, la estética y ritualidad prehispánica que tanto admiraba y los recuerdos de nuestras excavaciones en la desembocadura del río Loa. Por cierto, no faltaba el fin de las dictaduras y el retorno de la democracia, nuestros amigos muertos y los tiempos de cambios. Así, hasta que el triángulo entre sus chocolates, los tabacos cubanos y el whisky más genuino se agotaba, justo en una amanecida cuando le exigía que me indicara precisamente donde ocurrió eso del tango "Sur paredón y después"...

Vivía intensamente los sucesos del pasado desde una arqueología que debía ser válida para la sociedad de hoy, y en ese pasaje le preocupaba el destino democrático de su país por su espíritu esencialmente republicano, de mente abierta y tolerante. De tanta lealtad consigo mismo es que nunca olvidó el escenario que lo condujo hacia el exilio mexicano.

Pepe Pérez para sus más cercanos, nació en Córdoba en un ambiente familiar ordenado por su padre médico quien lo motivó para su ingreso al colegio Montserrat donde se graduó de bachiller. De allí tuvo un coqueteo con la Facultad de Arquitectura, pero se licenció en Historia en 1967 con una tesis en arqueología relativa a los patrones de poblamiento en el noroeste argentino. Su doctorado de 1977, en la Universidad Nacional de Córdoba, se orientó a la alfarería del sitio Ciénaga Grande en Jujuy, bajo la célebre influencia del maestro de su generación, el Dr. Alberto Rex González, quien lo involucró, a toda pasión, en la problemática arqueológica del noroeste argentino. Precisamente con él escribió varios artículos y un libro que fue nuestra consulta obligada por 1972: Argentina indígena. Vísperas de la conquista.

Precisamente conocí a Pepe por Alberto Rex cuando en 1963, en el congreso de arqueología de San Pedro de Atacama, advirtió en la cerámica fragmentada recogida por Le Paige, tiestos Aguada entre otros componentes trasandinos. Alberto había formado a las primeras generaciones de Rosario y Córdoba. Al tiempo llegó Myriam Tarragó para iniciar su famosa tesis doctoral en el museo de San Pedro de Atacama y luego asistimos al primer congreso de arqueología argentina, en Rosario (1970), y por intermedio de Myriam nos rodeamos de esos jóvenes que marcaron un antes y un después de la arqueología del NOA, entre

1 Instituto de Investigaciones Arqueológicas y Museo. Universidad Católica del Norte, San Pedro de Atacama, Chile. 
estos: Pepe Pérez, Ana María Lorandi, Víctor Núñez Rigueiro y Osvaldo Heredia. En este elenco fue Pepe el investigador que más cerca estuvo de Alberto Rex compartiendo terrenos, publicaciones y esperanzas hasta el final. Con esa generación fue fácil compartir y crear contactos informales hasta complejos eventos binacionales bajo la disciplina de Myriam y el entusiasmo de Pepe, con todo el respaldo de los colegas del Museo Etnográfico, prevaleciendo siempre la consigna desde los inicios: una arqueología sin fronteras, con teorías, metodologías y técnicas actualizadas y adecuadas a la praxis de ese tiempo.

Su formación le permitía una amplia mirada desde la historia, arqueología, antropología y el arte, aplicado en el pasado indígena del noroeste argentino, enmarcado en el mundo andino, alcanzando una nueva valoración interpretativa de la cultura Aguada mediante su lectura iconográfica. En general, los discos metálicos fueron sus imágenes casi familiares, como los "suplicantes", es decir, donde registraba un mensaje ritual más que enredarse en estilos, desde un tiesto cerámico a un monolito grabado él llegaba al fondo, a las interpretaciones ideológicas donde solo algunos elegidos tienen esa capacidad para introducirse en el alma de la sociedades muertas.

$\mathrm{Su}$ trayectoria académica siguió el curso progresivo desde Becario, Investigador Principal y Asesor del CONICET (1988-9 y 1997-8); dedicándose desde 1987 al 2005 a la Dirección del Museo Etnográfico de la Universidad de Buenos Aires y posteriormente, desde el 2005 al 2013, en la conducción del Museo Histórico Nacional de la capital. A su regreso de su exilio en México se incorporó al CONICET y a la Facultad de Filosofía y Letras de la Universidad de Buenos Aires como Profesor Titular de Historia de América I en el Departamento de Historia (1997-1998).

Entre sus actividades docentes tanto en Argentina como en el extranjero destacamos su decidida participación en los programas académicos de la Fundación Antorchas, en el área de Humanidades, donde asesoró al comité de selección de becas y subsidios (1993-6). Por lo mismo, numerosos investigadores jóvenes se formaron bajo sus orientaciones. Fue becario Fulbright y evaluador de múltiples proyectos en la Universidad Nacional de Quilmes, Universidad Nacional del Centro de la Provincia de Buenos Aires-Tandil y de la Universidad Nacional de Buenos Aires.
Sus labores fueron múltiples, participando como Miembro del Jurado de la Fundación para la Investigación del Arte Argentino (2001 y 2004), Co-coordinador de proyectos de la Agencia Nacional de Promoción Científica y Tecnológica (2005), Director del Proyecto de The Rockefeller Foundation sobre museos argentinos durante 1880-1930 (19972001) y asesor de proyectos de las Universidades Nacionales de Córdoba, Buenos Aires, La Plata y Rosario. Finalmente, no faltó a los congresos de arqueología en Argentina y países vecinos, mientras tanto asesoraba a los museos de Argentina, Chile, Suecia y Nueva Zelanda.

Investigó en el noroeste argentino, norte de Chile y el centro de México, dando lugar a múltiples aportes. Publicó más de sesenta artículos en revistas argentinas y extranjeras, con certeza ocho libros y tres capítulos, entre estos recordamos: Argentina Indígena. Vísperas de la conquista, con Alberto Rex González (1993); Presencia de Vere Gordon Childe (1981); Etnohistoria en Mesoamérica y los Andes, con Juan Manuel Pérez Zevallos (1987); El jaguar en llamas. La religión en el antiguo Noroeste argentino (2000); Latin American Archaeology, from Colonialism to Globalization, con Gustavo Politis (2004); y acompañó a José Luis Lorenzo con Lorena Mirambell en Prehistoria y arqueología (1991), entre otros.

De mis lecturas obligadas quisiera destacar dos artículos muy innovadores para esa época del valioso binomio Pérez y Heredia: el primero vinculado con sus investigaciones en Ambato (Catamarca), y el segundo el replanteo de la Cultura de la Aguada, también publicado en 1987. Paralelamente participó en el comité editorial de Ciencia Hoy por más de una década.

De todas sus publicaciones hay una sorprendente para entender hasta dónde logró introducirse en el mundo andino. Quedó tan impresionado con la ópera argentina "Chasca", tramada en tiempo de los incas, cuyo mérito mayor radica en ser creada en un país precisamente marcado por la lírica europea. Chasca es hija de Viracocha y este la obliga a casarse con Pachacutec. Chasca ama a otro: mata a quien desprecia. Su padre debe inmolarla... La obra dio lugar a un libro donde su artículo "Chasca o la atracción del americanismo" le otorgó el necesario contexto antropológico e histórico.

Sin duda que sabía unir como nadie esa línea tan delicada entre arte y arqueología, docencia e investigación y formación sin subordinar a sus 
alumnos y becarios, entregándoles su amistad evitando los excesos del boato académico con una honestidad a toda prueba, pero cuidado con algún juicio polémico porque ahí tenía la oportunidad de soltar su inolvidable mirada de jaguar. No podía soportar la intolerancia ni menos las presiones del poder, venga de donde venga.

Estaba en su plena creatividad académica cuando decide exiliarse en México durante el último gobierno militar. Allí se desempeñó en el Distrito Federal como investigador y docente en el Instituto Nacional de Antropología e Historia (1977-1982) y en la Escuela Nacional de Antropología e Historia (1985-1969). Fue en México donde se plasmó un movimiento latinoamericano que venía en marcha para valorar la arqueología desde una perspectiva social. Ciertamente en 1975 Pepe Pérez participó en el encuentro de Teotihuacán, para definir a la arqueología como ciencia social, bajo la inspiración de Luis Lumbreras, José Luis Lorenzo y los escritos del pionero Gordon Childe, junto a un grupo de arqueólogos latinoamericanos que aspiraban en un espacio de libertad para debatir y encarar los objetivos sociales, desde una arqueología con sentido histórico, segregada de la antropología colonialista, al interior del materialismo histórico. En esta dirección él era experto en el legado de Gordon Childe, de modo que sus juicios fueron estimulantes. No obstante, como todo exiliado su mente estaba en su país y pronto organizó la famosa exposición y traslado de las cabezas colosales Olmecas por medio de la Fundación Proa.

Siempre mantuvo una alta valoración por el arte prehispánico, aspecto que sería obvio para un arqueólogo, a no ser que en Argentina la historia de las creaciones precolombinas no era tan conocida. Le había seguido la pista a las piezas más célebres tanto públicas como privadas. Disfrutaba cada vez que podía exhibir aquellas expresiones estéticas que venían de lo que se creía eran obras de seres primitivos, sino salvajes. $\mathrm{Al}$ respecto fue muy comentada su curaduría del arte indígena del noroeste argentino: Arte originario. Diversidad y memoria, precisamente nada menos que en el Museo Nacional de Bellas Artes, con piezas que cubrían 2.500 años de trayectoria (cerámica, lítica y bronce). Aspiraba a explicar por qué los argentinos no sienten que el mundo indígena sea parte de su propia historia cultural.

De acuerdo con la proyección social que esperaba de las investigaciones arqueológicas, siguiendo con los idearios que compartimos en nuestra generación, le otorgó una gran importancia al rol de los museos, entregando su mejor tiempo para dirigir al Etnográfico y al Histórico en Buenos Aires. Aún más, llevado por su acercamiento a una estética museográfica valoró las colecciones arqueológicas de alto valor patrimonial. En efecto, fue Miembro del Comité museográfico del National Museum of the American Indian de la Smithsonian Institution de Washington (1997). Fue encargado de organizar la exposición del arte precolombino durante el Congreso Internacional de Americanistas de 1966. También fue curador de la exposición del arte precolombino en Argentina, en el Museo de Arte Hispanoamericano (1994) y de la exposición Los sueños del jaguar, en el Museo Chileno de Arte Precolombino (1994-1995). Finalmente fue curador de diversas exposiciones: Caminos sagrados; De la Puna al Chaco; Culturas del Gran Chaco; La magia de la risa y el juego en el arte prehispánico de Veracruz, entre los años 1997 al 2005.

Cuando retornó al país en 1987 se hizo cargo de la Dirección del Museo Etnográfico de la Universidad de Buenos Aires. En 2005 dejó esa dirección para asumir la del Museo Histórico Nacional hasta el 2012. En ambas instituciones llevó a cabo una labor pionera superando los estándares de preservación y catalogación, diseño y renovación de las temáticas exhibidas. Fuera de dudas transformó sus espacios en activos de memoria y reflexión, proyectados al presente. En 1987 Pepe Pérez junto a Marta Dujovne replantearon la propuesta museológica en el Museo Etnográfico.

He intentado rescatar algunas de sus frases que reflejen lo que Pepe Pérez pensaba últimamente acerca de esa impronta que marcó a nuestras generaciones: no basta ser un buen arqueólogo, sino buscar siempre cómo traducimos nuestros conocimientos a la sociedad que nos envuelve. Él era partidario de comprender su país con un criterio multiétnico y pluricultural, por medio de diversas etapas. Desde una población autóctona a la colonización española, siguiendo con la inmigración europea y de países vecinos, además de los movimientos internos. Estos procesos históricos y culturales deberían representar a todos los argentinos, considerando que este es un país amplio y variado, con historias regionales importantes. Obviamente que la Patagonia no es lo mismo que el Chaco. En este sentido siempre observó que no era recomendable evaluar estos procesos con prejuicios y concepciones ideologizadas. 
Así la evaluación del pasado no podría ser juzgada críticamente desde el presente, sino analizando detenidamente los contextos históricos y antropológicos de cada época.

Con respecto a los museos sus declaraciones recientes fueron también clarividentes. Indicaba que era necesaria su total independencia de los poderes de turno, para detallar la real pluralidad en la interpretación del pasado. En el caso de los museos de la Nación, estos deberían reflejar el quehacer histórico de todas las provincias y no solamente las visiones centralistas. El aceptaba que los museos deberían ser centros que rescatan, investigan y valorizan las realidades del pasado y presente con miras a su proyección a la población al interior de un mensaje crítico. Pensaba que era conveniente eliminar el mito de los museos como lugares exclusivos para académicos e intelectuales, sino abiertos a la comunidad.

La última vez que lo visité en el edificio patrimonial del Museo Histórico de la capital federal tocamos tantos temas, desde cómo restaurarlo y habilitar nuevas salas, buscando siempre las miradas plurales e innovaciones museográficas. Comentábamos que no es fácil romper con las orientaciones patrimoniales de las élites y esas tendencias tan capitalinas de no reconocer los complejos procesos de la evolución social de las sociedades en sus diversos paisajes culturales regionales por los excesos del centralismo y ni hablar de nuestras leyes patrimonialistas obsoletas. ¿Cómo abrir un gran debate para democratizar el patrimonio con fondos y estrategias que armonicen las visiones "nacionales" y "regionales"? ¿Qué hacer para no manipular los pasados recientes y más antiguos?

Ocurrió que el robo del reloj del general Manuel Belgrano desde el Museo Histórico Nacional levantó la oportunidad que esperaba el oficialismo para retirarlo del cargo. No se difundieron sus aportes. Fue entonces, que un académico de enorme prestigio, unos años antes de su deceso, debió mostrar los dientes del jaguar con una ardiente defensa y una campaña solidaria de apoyo incondicional.

Su renuncia obligada por presiones políticas y burdos pretextos, trajo consigo un efecto contrario. El apoyo fue total demostrado en una declaración firmada por más de un centenar de destacados académicos de la capital. Resultan pertinentes algunos de sus juicios sobre el rol de los museos en esos días tormentosos. Opinaba que la noción de museo no es compatible con los criterios populistas sino buscando la verdad con un lenguaje al alcance de todos. Los criterios revisionistas se deberían excluir por valorar solo ciertas versiones de la Historia. En este sentido era enfático al indicar que los revisionistas antes de empezar a valorar un proceso cultural o histórico ellos ya saben de antemano cuál será el resultado. Siempre nos enfatizaba que en su país no era fácil aceptar la diversidad, donde los indígenas y los afroamericanos han sido excluidos y frente al reconocimiento de los pueblos originarios, reconocía que aun son perseguidos. Con respecto a los pueblos originarios precisamente era partidario de lograr vínculos comprometidos, acción notable si se acepta que desde el exterior Argentina suele verse como un país de emigrantes. A raíz de los 25 años de la revista Ciencia Hoy, los colegas Pérez, Politis y Nastri han sostenido que es necesario buscar las alianzas necesarias para establecer ese indispensable acompañamiento entre la academia y los intereses de los herederos del patrimonio cultural, sea cual sea, incluyendo por cierto el arqueológico. $\mathrm{Al}$ respecto señalaron acertadamente que los yacimientos y los objetos no son sólo datos para reconstruir el pasado:

hoy son concebidos como patrimonio cultural, con un valor simbólico más complejo y amplio que el de meros objetos de estudio. Ese patrimonio, a su vez, se ha transformado en un ámbito de memoria en el que los pueblos originarios y las comunidades locales recrean espacios del pasado y del presente.

En este sentido la proyección social de la investigación la advirtieron como una posibilidad del acceso al desarrollo local a través de prácticas de turismo cultural y, por lo tanto, con tácticas proteccionistas organizadas de abajo hacia arriba, con la debida capacitación y protagonismo de las comunidades locales.

Hemos dejado para el final su notable gesto frente a las "Madres de Plaza de Mayo". Por ser de la generación que vivió intensamente las dictaduras y las sufría donde éstas se habían incrustado. A penas logró crear el espacio adecuado en el Museo Histórico Nacional abre las puertas cuando en el año 2007 inauguraron la exposición fotográfica Pariendo vida en imagines. Su sentido de la solidaridad también se reflejó en el año 2011 cuando se involucró con el Primer Encuentro Nacional de Trabajadores de Museos realizado en el mismo museo. Allí acogió a un centenar de trabajadores arribados desde distintas regiones de la Argentina y otros países latinoamericanos. 
En suma, su obra se sustentó en sus enseñanzas, libros, artículos, trabajos de campo y exposiciones centradas en la arqueología del noroeste argentino y en la valoración del patrimonio cultural. Qué duda cabe que Pepe Pérez se pensó in profundis la larga historia en plural de Argentina. Para nosotros había algo más. Una larga amistad personal capaz de confidenciarnos todo, como aquella noche iquiqueña junto al Pacífico, en que Lucho Lumbreras, para variar, nos involucraba en sus proyectos y que por cierto nos juramentamos hacerlo: el Museo Inca en Cusco, con la participación de todos los espacios y sociedades del sur andino... Definitivamente hemos sido y somos soñadores profesionales y en esto Pepe Pérez no fue una excepción.
José (Pepe) Pérez Gollán falleció el 23 de mayo del 2014 buscando a su gran amigo Osvaldo (Negro) Heredia, después de un prolongado silencio, porque todas sus energías las orientó para vencer en esa lucha vital y fatal. No fue atrapado. Vive en nuestras memorias entre el aroma de su tabaco y un artículo que no alcanzamos a escribir reltivo a La ruta de los Dioses, sustentado en el tráfico trasandino de "sus" alucinógenos del oriente. Él sabe que nos encontraremos por el norte para hartarnos de la arqueología andina que nos gusta y de paso nos devuelva su más tierna sonrisa... Definitivamente se ha trasformado en un guerrero Aguada para asustar con sus jaguares a aquellos que creen en el abismo entre ciencia y conciencia social. 
